\title{
Article
}

\section{Differentiation of Benign and Malignant Breast Lesions Using ADC Values and ADC Ratio in Breast MRI}

\author{
Silvia Tsvetkova ${ }^{1, *(D)}$, Katya Doykova ${ }^{1}\left(\mathbb{D}\right.$, Anna Vasilska ${ }^{1}$, Katya Sapunarova ${ }^{2}$, Daniel Doykov ${ }^{3}$, \\ Vladimir Andonov ${ }^{3}$ and Petar Uchikov ${ }^{4}$ (D)
}

check for updates

Citation: Tsvetkova, S.; Doykova, K.; Vasilska, A.; Sapunarova, K.; Doykov, D.; Andonov, V.; Uchikov, P.

Differentiation of Benign and

Malignant Breast Lesions Using ADC Values and ADC Ratio in Breast MRI. Diagnostics 2022, 12, 332. https:// doi.org/10.3390/diagnostics12020332

Academic Editor: Graziella Di Grezia

Received: 30 December 2021

Accepted: 26 January 2022

Published: 27 January 2022

Publisher's Note: MDPI stays neutral with regard to jurisdictional claims in published maps and institutional affiliations.

Copyright: (C) 2022 by the authors. Licensee MDPI, Basel, Switzerland. This article is an open access article distributed under the terms and conditions of the Creative Commons Attribution (CC BY) license (https:// creativecommons.org/licenses/by/ $4.0 /)$.
1 Department of Diagnostic Imaging, Medical University Plovdiv, 15-A Vasil Aprilov Blvd, 4002 Plovdiv, Bulgaria; katya.doykova@mu-plovdiv.bg (K.D.); anna.vasilska@mu-plovdiv.bg (A.V.)

2 First Department of Internal Diseases, Medical University Plovdiv, 15-A Vasil Aprilov Blvd, 4002 Plovdiv, Bulgaria; katya.sapunarova@mu-plovdiv.bg

3 Second Department of Internal Diseases, Medical University Plovdiv, 15-A Vasil Aprilov Blvd, 4002 Plovdiv, Bulgaria; daniel.doykov@mu-plovdiv.bg (D.D.); vladimir.andonov@mu-plovdiv.bg (V.A.)

4 Department of Special Surgery, Medical University Plovdiv, 15-A Vasil Aprilov Blvd, 4002 Plovdiv, Bulgaria; puchikov@yahoo.com

* Correspondence: sts2001@abv.bg

\begin{abstract}
Magnetic resonance imaging (MRI) of the breast has been increasingly used for the detailed evaluation of breast lesions. Diffusion-weighted imaging (DWI) gives additional information for the lesions based on tissue cellularity. The aim of our study was to evaluate the possibilities of DWI, apparent diffusion coefficient (ADC) value and ADC ratio (the ratio between the ADC of the lesion and the ADC of normal glandular tissue) to differentiate benign from malignant breast lesions. Materials and methods: Eighty-seven patients with solid breast lesions (52 malignant and 35 benign) were examined on a $1.5 \mathrm{~T}$ MR scanner before histopathological evaluation. ADC values and ADC ratios were calculated. Results: The ADC values in the group with malignant tumors were significantly lower (mean $0.88 \pm 0.15 \times 10^{-3} \mathrm{~mm}^{2} / \mathrm{s}$ ) in comparison with the group with benign lesions (mean $1.52 \pm 0.23 \times 10^{-3} \mathrm{~mm}^{2} / \mathrm{s}$ ). A significantly lower ADC ratio was observed in the patients with malignant tumors (mean $0.66 \pm 0.13$ ) versus the patients with benign lesions (mean $1.12 \pm 0.23)$. The cut-off point of the ADC value for differentiating malignant from benign breast tumors was $1.11 \times 10^{-3} \mathrm{~mm}^{2} / \mathrm{s}$ with a sensitivity of $94.23 \%$, specificity of $94.29 \%$, and diagnostic accuracy of $98 \%$, and an ADC ratio of $\leq 0.87$ with a sensitivity of $94.23 \%$, specificity of $91.43 \%$, and a diagnostic accuracy of $95 \%$. Conclusion: According to the results from our study DWI, ADC values and ADC ratio proved to be valuable additional techniques with high sensitivity and specificity for distinguishing benign from malignant breast lesions.
\end{abstract}

Keywords: breast MRI; DWI; ADC value; ADC ratio; breast lesions

\section{Introduction}

Breast soft tissue lesions often represent a diagnostic challenge in daily practice. Covering a wide spectrum of histological conditions, they are broadly subdivided into malignant and benign tumor lesions. Breast cancer is the most common malignancy in the female population [1,2] and was even reported to be the most common malignancy in the world for both sexes in 2020, accounting for $11,7 \%$ of all newly diagnosed malignancies, closely followed by lung cancer (11.4\%) [2]. Early diagnosis, including interventional procedures for histological confirmation, is crucial for a better outcome of the disease. On the other hand, following histological examination, lesions in the breast are frequently confirmed to be benign in origin, so unnecessary biopsies are often reported [3,4]. In this aspect, applying a non-invasive imaging technique with a high diagnostic potential is of great importance to avoid unnecessary interventional procedures and reduce costs, solving the dilemma of whether it is a malignant or non-malignant lesion [5-7]. Magnetic resonance 
imaging (MRI) of the breast has been used increasingly during the last decade as a preferred problem-solving method in complicated and unclear cases such as in women with "dense breast", multiple lesions, the evaluation of residual tumor, recurrence or granulation tissue after intervention [8-10], due to its ability to reveal both the morphologic structure and the kinetic properties of the pathologic lesion $[8,11]$.

Diffusion-weighted imaging (DWI) is a fast non-contrast MRI technique based on the free movement of water molecules in the extracellular space and reflects tissue cellularity. The motion of water molecules is more restricted in tissues with high cellularity and less restricted in areas of low cellularity [12,13]. Based on this characteristic, DWI can create contrast images that differ from the conventional T1- and T2-weighted images. Signal intensity in diffusion-weighted imaging is inversely proportional to the degree of water molecule diffusion [14], which means that structures with high cellularity and restriction in diffusion will present with a more intense signal. Furthermore, DWI allows the quantitative evaluation of water diffusion, using the apparent diffusion coefficient (ADC). Its value is calculated in square millimeters per second $\left(\mathrm{mm}^{2} / \mathrm{s}\right)$ and can be measured by assessing the signal attenuation that occurs at diffusion-weighted imaging performed with at least two different $b$ values [14]. Breast cancer usually presents with a restricted diffusion of water molecules which leads to increased DWI signal. The ADC value is lower as compared to normal breast tissue and benign lesions of the breast [14,15]. High ADC values are rarely reported in malignant lesions $[16,17]$. Some authors additionally used the ADC ratio between the ADC value of the lesion and ADC value of normal breast glandular tissue to further evaluate the diagnostic performance of DWI [18,19].

However, data in the literature on the diagnostic potential of the applied technique show some discrepancies, not only in terms of its sensitivity and specificity. Studies have also demonstrated some inconclusiveness regarding the ADC value threshold that could be trusted when attempting to non-invasively differentiate malignant from benign breast lesions [20,21].

Based on the existing discrepancies, in our study, we aimed to evaluate the role of DWI, ADC value and ADC ratio in the differentiation of benign from malignant breast lesions in patients with proven histopathological diagnoses.

\section{Materials and Methods}

\subsection{Patients}

This retrospective observational study includes 87 patients with solid breast lesions diagnosed by mammography or breast ultrasound that needed further assessment. They were referred to breast MRI during the period of January 2018-July 2021. All MRI examinations were performed prior to biopsy procedures. The absence of subsequent biopsy and histological findings was the main exclusion criterion. Nine patients had a Tru-cut biopsy, while 78 patients underwent excisional biopsy. The type of biopsy was decided by the surgeon. Tru-cut biopsy was chosen as a less invasive method as compared to excisional biopsy and was performed using a Tru-cut gun with an 18-gauge needle. The tissue specimen included four consecutive insertions of the needle in the lesion, while excisional biopsy usually removed the whole lesion or pathologic region. All patients signed written informed consent for all procedures.

\subsection{MRI Protocol}

All MRI examinations were acquired on a 1.5 T MRI scanner (Magnetom Amira, Siemens Healthcare, Erlangen, Germany) using an 18-channel dedicated breast coil. Patients were examined in a prone position, head first. The standardized MRI protocol included the following sequences: non-fat-suppressed T1-weighted transversal sequence; fat-suppressed turbo inversion recovery magnitude (TIRM) transversal sequence; fatsuppressed dynamic contrast-enhanced 3D T1-weighted fast low angle (FL) transversal sequence. A gadolinium contrast agent was injected $(0.1 \mathrm{mmol} / \mathrm{kg})$ and 1 pre-contrast and 6 post-contrast series were performed with a slice thickness of $1.5 \mathrm{~mm}$. Subtraction images 
were also acquired by subtracting the post-contrast images from the first images. Time signal intensity curves of the lesions were also obtained from the dynamic series. As a basic sequence of evaluation in the study, DWI was performed prior to the dynamic contrast examination with the following parameters: field of view (FOV) $420 \times 200 \mathrm{~mm}$, time of repetition (TR) $5400 \mathrm{~ms}$, TE $53 \mathrm{~ms}$, matrix size $160 \times 61$, slice thickness $4 \mathrm{~mm}$, and scanning time $232 \mathrm{~s}$. The diffusion-weighted sequences were performed in the axial plane with $3 \mathrm{~B}$ values $\left(B=50,500,800 \mathrm{~mm}^{2} / \mathrm{s}\right)$. ADC maps were received during the examination and ADC values were calculated using software provided by the manufacturer (Syngo, Siemens Healthcare, Erlangen, Germany).

\subsection{ADC Value Measurement}

ADC values of the lesions were measured by manually placing regions of interest (ROIs) within the lesion on the ADC map. Multiple ROIs were placed and the ROI with the lowest ADC value was selected. We avoided central regions with necrosis and obvious cystic areas within the lesion as well as the most peripheral areas to avoid partial volume effects. Areas with obvious artifacts were also avoided. When identifying the solid part of the tumors, we used as reference images those from the dynamic contrast-enhanced MRI (DCE MRI), usually the third post-contrast series and the subtraction image. The ADC value of normal glandular tissue was assessed on the contralateral breast except for one patient who had previous mastectomy. After that, we calculated the ADC ratio which is the ratio between the ADC of the lesion and ADC of the normal glandular tissue. The assessment was performed by one qualified radiologist with 4 years of experience in breast MRI.

\subsection{Pathohistological Evaluation}

All 87 patients had a final diagnosis based on histological examination obtained after Tru-cut or excisional biopsy. The pathohistological report assessed the lesion type (benign or malignant) and detailed histological findings.

\subsection{Statistical Analysis}

The data analysis was performed with the statistical software IBM SPSS version 27 (Chicago, IL, USA, 2020) and MedCalc version 20.014 (MedCalc Software Ltd., Ostend, Belgium, 2021). Continuously measured variables (age, ADC, ADC ratio) were normally distributed (Kolmogorov-Smirnov's $p>0.05$ for all variables) and were described through the mean values and standard deviations. These variables were compared between the patients with malignant and benign tumors through t-tests for independent samples. A receiver operating characteristic (ROC) curve was used to establish the cut-off ADC value and ADC ratio for distinguishing malignant from benign tumors with the corresponding levels of sensitivity and specificity. All statistical tests were two-tailed and performed at a level of significance alpha $=0.05$. The statistical significance was marked as follows: ${ }^{*}-p<0.05 ;{ }^{* *}-p<0.01 ;{ }^{* * *}-p<0.001$.

\section{Results}

This study included 87 patients with a mean age of $48.05 \pm 8.23$ years (range 21 to 60 years). All patients had a breast MRI including both DCE MRI and DWI. Based on the histological evaluation (Table 1), 52 (59.76\%) of the patients were diagnosed with malignant tumors, of which the most frequent type $(n=36)$ was invasive ductal carcinoma (IDC). The remaining $35(40.24 \%)$ patients had benign lesions, among which the most frequent type was fibroadenoma $(n=12)$. The mean age of the patients with malignant tumors was significantly higher (49.79 \pm 7.87 years, range of $24-60$ years old) in comparison to the patients with benign lesions ( $45.45 \pm 8.17$ years, range of $21-60$ years old), $p=0.015$. 
Table 1. Histopathological data.

\begin{tabular}{|c|c|c|c|}
\hline & Histopathological Findings & Frequency & Percentage \\
\hline \multicolumn{4}{|c|}{ Malignant } \\
\hline 0 & Invasive ductal carcinoma & 36 & 41.40 \\
\hline 0 & Invasive lobular carcinoma & 5 & 5.75 \\
\hline 0 & Ductal carcinoma in situ (DCIS) & 3 & 3.45 \\
\hline 0 & Inflammatory carcinoma & 2 & 2.30 \\
\hline 0 & Medullary carcinoma & 2 & 2.30 \\
\hline 0 & Anaplastic carcinoma & 1 & 1.14 \\
\hline 0 & Mucinous carcinoma & 1 & 1.14 \\
\hline 0 & Papillary carcinoma & 1 & 1.14 \\
\hline & Tubular carcinoma & 1 & 1.14 \\
\hline & Total & 52 & $59.76 \%$ \\
\hline \multicolumn{4}{|c|}{ Benign } \\
\hline 0 & Fibroadenoma & 12 & 13.8 \\
\hline 0 & Abscess & 3 & 3.45 \\
\hline 0 & Apocrine metaplasia & 3 & 3.45 \\
\hline 0 & Sclerosing adenosis & 3 & 3.45 \\
\hline 0 & Fibrosis & 3 & 3.45 \\
\hline 0 & Fibrocystic changes & 3 & 3.45 \\
\hline 0 & Postoperative granular tissue & 3 & 3.45 \\
\hline 0 & Intraductal papilloma & 2 & 2.30 \\
\hline 0 & Fat necrosis & 2 & 2.30 \\
\hline & Inflamed cyst & 1 & 1.14 \\
\hline \multicolumn{2}{|r|}{ Total } & 35 & $40.24 \%$ \\
\hline
\end{tabular}

The ADC values in the group with malignant tumors were significantly lower (mean $0.88 \pm 0.15 \times 10^{-3} \mathrm{~mm}^{2} / \mathrm{s}$; range 0.60 to $1.30 \times 10^{-3} \mathrm{~mm}^{2} / \mathrm{s}$ ) in comparison with the group with benign lesions (mean $1.52 \pm 0.23 \times 10^{-3} \mathrm{~mm}^{2} / \mathrm{s}$; range 0.99 to $2.01 \times 10^{-3} \mathrm{~mm}^{2} / \mathrm{s}$ ), $p<0.001$. One of the 52 malignant tumors showed an ADC value of $1.30 \times 10^{-3} \mathrm{~mm}^{2} /$ and it was ductal carcinoma in situ (DCIS), and one of the 35 benign lesions (an abscess) had an $\mathrm{ADC}$ value of $0.89 \times 10^{-3} \mathrm{~mm}^{2} / \mathrm{s}$ (Figure 1 ).

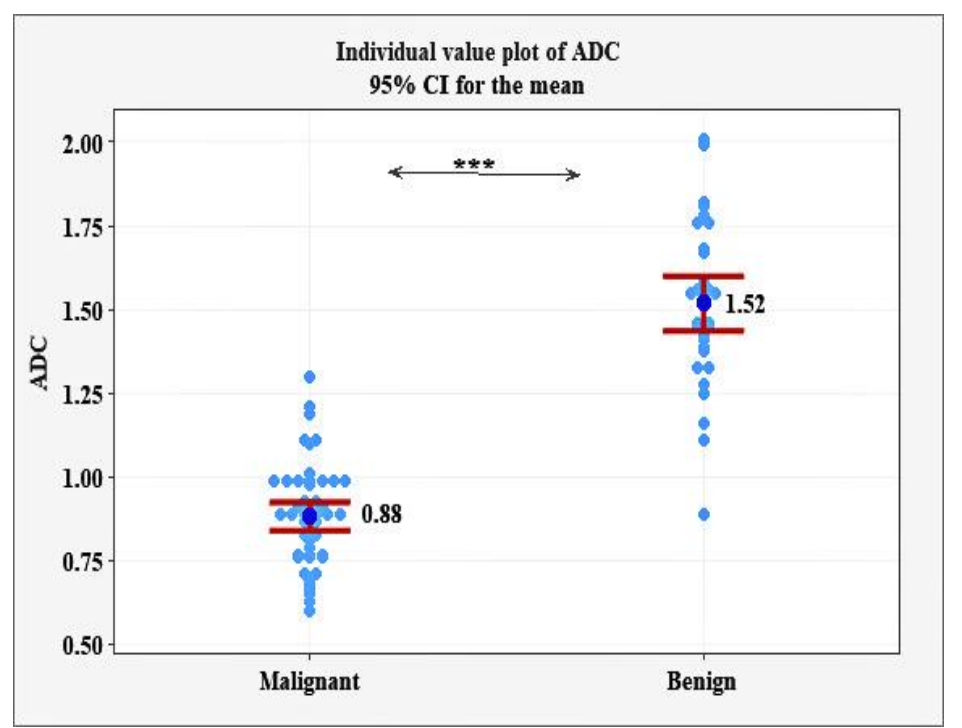

Figure 1. Individual and mean ADC values in the patients with malignant and benign tumors, *** $p<0.001$.

The analysis with the receiver operating characteristic (ROC) curve determined ADC $\leq 1.11 \times 10^{-3} \mathrm{~mm}^{2} / \mathrm{s}$ as the optimum cut-off value distinguishing malignant from be- 
nign tumors with a sensitivity of $94.23 \%$, a specificity of $94.29 \%$, and a very high diagnostic accuracy of $98 \%(\mathrm{AUC}=0.981,95 \% \mathrm{CI}$ : 0.928 to $0.998, p<0.001)$ (Figure 2 ).

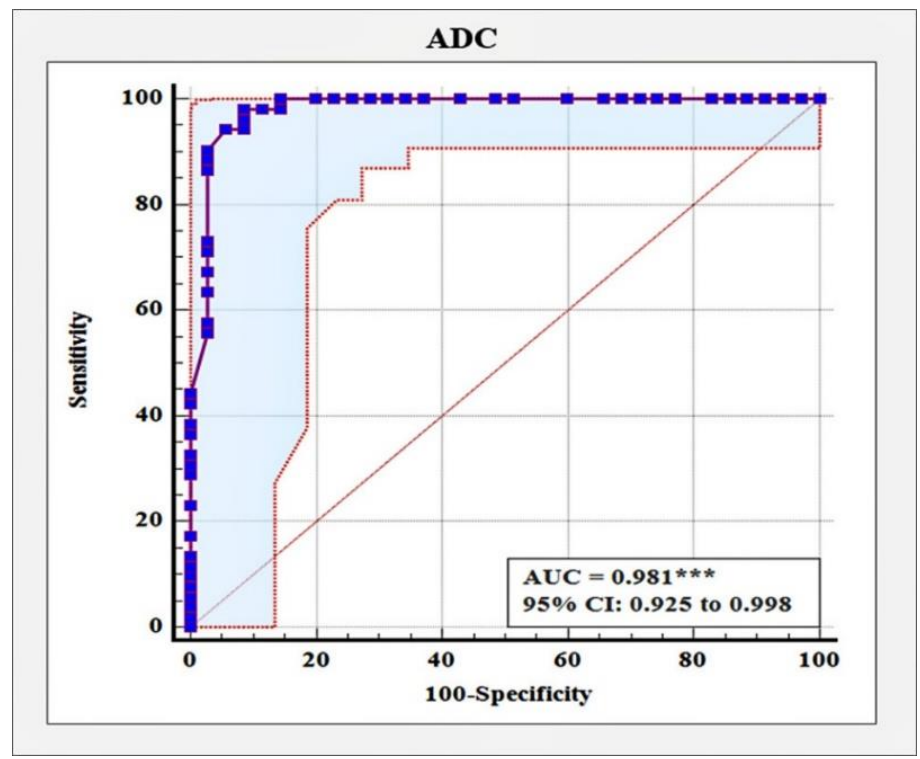

Figure 2. Receiver operating characteristic curve for distinguishing malignant from benign tumors based on ADC values, ${ }^{* * *} p<0.001$.

For normal fibroglandular tissue, the ADC values in the studied group of patients ranged between 0.99 and $1.72 \times 10^{-3} \mathrm{~mm}^{2} / \mathrm{s}$, with a mean of $1.36 \pm 0.16 \times 10^{-3} \mathrm{~mm}^{2} / \mathrm{s}$. A significantly lower ADC ratio was observed in the patients with malignant tumors (mean of $0.66 \pm 0.13$, range of $0.43-1.06$ ) versus the patients with benign lesions (mean $1.12 \pm 0.23$, range 0.54 to 1.79 ), $p<0.001$ (Figure 3 ).

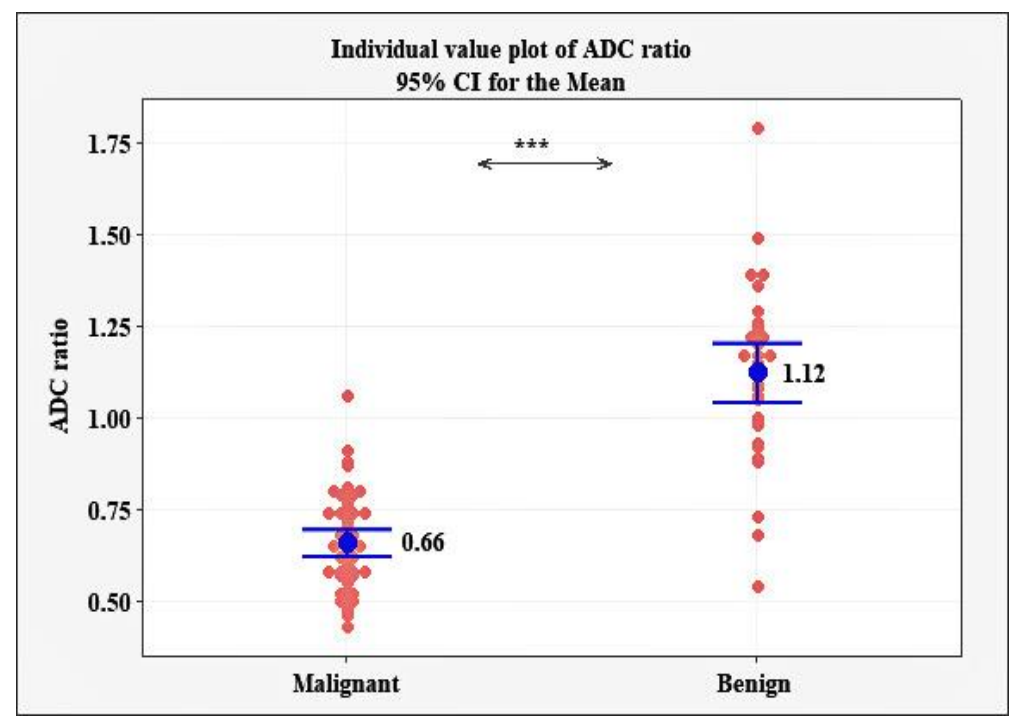

Figure 3. Individual and mean ADC ratio for the patients with malignant and benign tumors, *** $p<0.001$.

An ADC ratio cut-off point of $\leq 0.87$ was established as the optimum criterion for differentiating malignant from benign breast tumors, characterized by $94.23 \%$ sensitivity, $91.43 \%$ specificity, and a diagnostic accuracy of $95 \%$ (AUC $=0.950,95 \%$ CI: 0.881 to 0.985 , $p<0.001$ ) (Figure 4). 


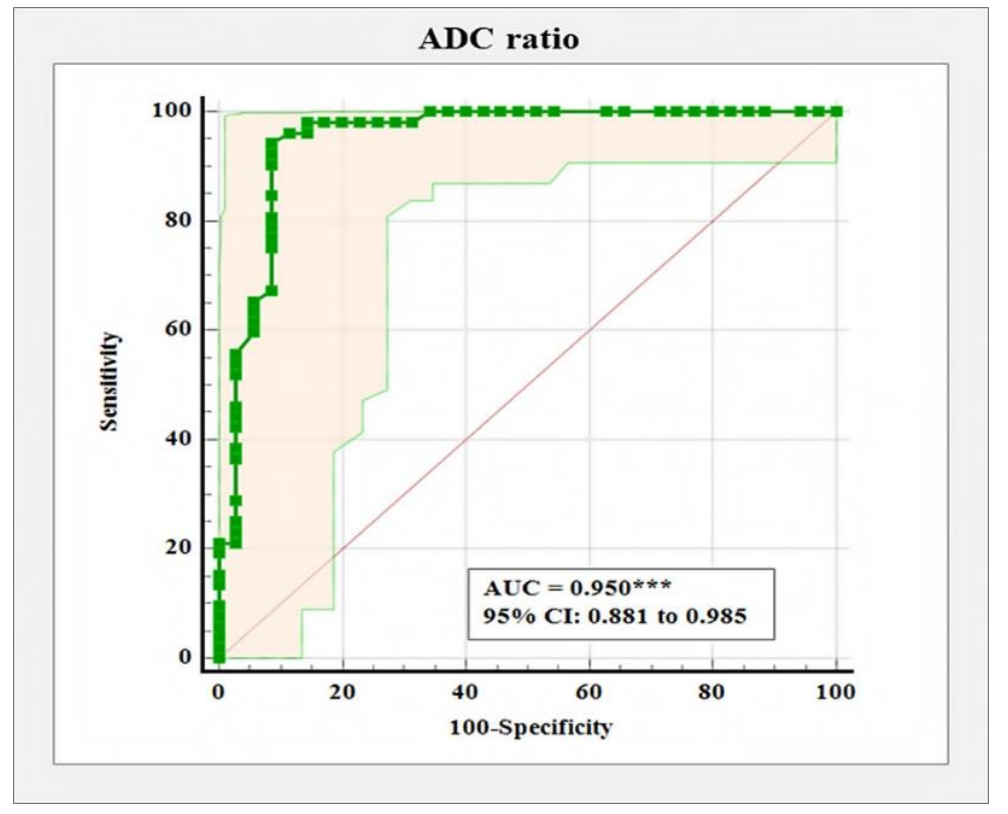

Figure 4. Receiver operating characteristic curve for distinguishing malignant from benign tumors based on ADC ratio, ${ }^{* * *} p<0.001$.

\section{Discussion}

MRI is a preferred problem-solving imaging method for the evaluation of complex and unclear breast lesions in women with "dense breast" or multiple lesions, in the evaluation of residual tumor, recurrence or granulation tissue due to its ability to assess both the morphologic structure and the kinetic properties of the pathologic lesions [8-11]. However, MRI has a high sensitivity but lower specificity (93\% and 71\%, respectively) [21] in the assessment of breast lesions. Recent studies [20-24] have suggested that the additional evaluation of the diffusion properties of breast lesions can improve specificity; ADC, measured in DWI, is thus being increasingly used as a marker in the detection and characterization of breast lesions [21]. Furthermore, other authors added to this additional ADC ratio calculation $[25,26]$. DWI and ADC values are determined by the decrease in the extracellular volume content of the tumors due to the increased cellular density and the fall in the ADC value is due to restricted water diffusion [26]. This is different structural information than that from the dynamic contrast-enhanced examinations whose results are directly related to the vascularity of the tumors and unrelated to tumor cellularity [26,27].

Our study evaluates the ADC values and ADC ratio of breast lesions in patients with benign and malignant tumors before the performance of biopsy procedures. The ADC values showed a significant difference $(p<0.001)$ between malignant and benign lesions. In the group with malignant tumors, they were significantly lower (mean $0.88 \pm 0.15 \times 10^{-3} \mathrm{~mm}^{2} / \mathrm{s}$; range 0.60 to $1.30 \times 10^{-3} \mathrm{~mm}^{2} / \mathrm{s}$ ) in comparison with the group with benign lesions (mean $1.52 \pm 0.23 \times 10^{-3} \mathrm{~mm}^{2} / \mathrm{s}$; range 0.99 to $2.01 \times 10^{-3} \mathrm{~mm}^{2} / \mathrm{s}$ ). Our results for malignant tumors are compatible with the reported range of mean ADC values in the literature varying from $0.83 \pm 0.19 \times 10^{-3} \mathrm{~mm}^{2} / \mathrm{s}$ to $1.52 \pm 0.23 \times 10^{-3} \mathrm{~mm}^{2} / \mathrm{s}[18,28,29]$. However, our results were closer to the results of Kim et al. [22] that reported ADC values of $0.87-0.93 \times 10^{-3} \mathrm{~mm}^{2} / \mathrm{s}$ and Akin et al. [25] $-0.83 \pm 0.19 \times 10^{-3} \mathrm{~mm}^{2} / \mathrm{s}$, which are higher than those reported by Maric et al. [23] $-0.68 \times 10^{-3} \mathrm{~mm}^{2} / \mathrm{s}$ and lower than those of Partridge et al. [28]-1.29 $\pm 0.26 \times 10^{-3} \mathrm{~mm}^{2} / \mathrm{s}$. These results may be due to the different technical parameters and different histological distribution in the studies. In our study, the lowest value $0.60 \times 10^{-3} \mathrm{~mm}^{2} / \mathrm{s}$ was in a 45 -year-old patient with invasive ductal carcinoma (Figure 5). 


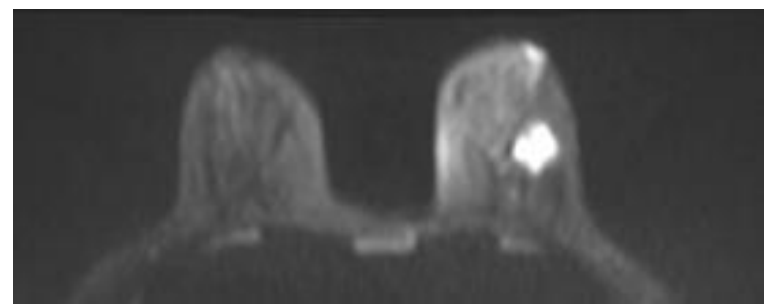

(A)

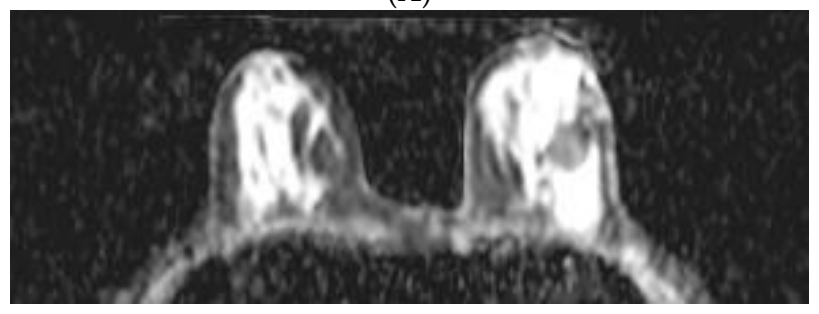

(B)

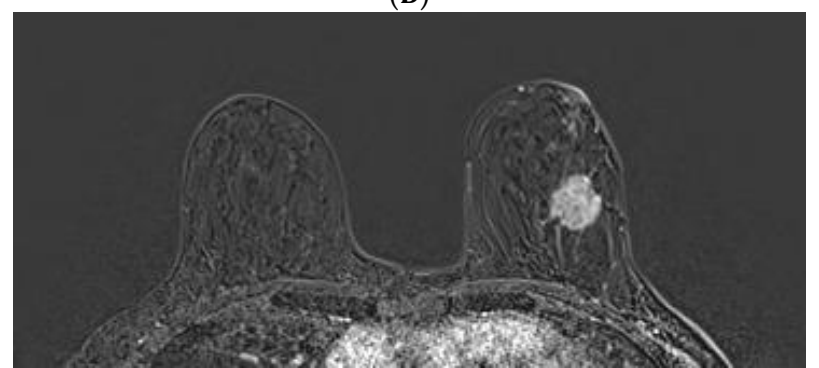

(C)

Figure 5. Breast MRI in a 45-year-old patient with invasive ductal carcinoma: (A) DWI (b = $\left.800 \mathrm{~mm}^{2} / \mathrm{s}\right)$; (B) ADC value $0.60 \times 10^{-3} \mathrm{~mm}^{2} / \mathrm{s}$; and (C) DCE-MRI (subtraction image).

The ADC values of benign tumors are also within the reported values from $1.41 \pm 0.24$ $\times 10^{-3} \mathrm{~mm}^{2} / \mathrm{s}$ to $1.72 \pm 0.43 \times 10^{-3} \mathrm{~mm}^{2} / \mathrm{s}[23,25,30,31]$.

Different studies reported varying results in ADC value sensitivity and specificity. We determined an ADC $\leq 1.11 \times 10^{-3} \mathrm{~mm}^{2} / \mathrm{s}$ as the optimum cut-off value for distinguishing malignant from benign tumors with a sensitivity of $94.23 \%$, a specificity of $94.29 \%$, and a very high diagnostic accuracy of $98 \%$ (AUC $=0.981,95 \% \mathrm{CI}: 0.928$ to $0.998, p<0.001$ ). A similar cut-off value of $1.1 \times 10^{-3} \mathrm{~mm}^{2} / \mathrm{s}$ was reported by Azab and Ibrahim [18], achieving a sensitivity of $89.75 \%$ and a specificity of $94.4 \%$, Akin et al. [25] $1.08 \times 10^{-3}$ $\mathrm{mm}^{2} / \mathrm{s}$ with sensitivity and specificity of $92 \%$ and $92 \%$, respectively, while Kul et al. [32] reported a cut-off value of $0.92 \times 10^{-3} \mathrm{~mm}^{2} / \mathrm{s}$ with a sensitivity of $91.5 \%$ and a specificity of $86.5 \%$. A meta-analysis based on 13,847 lesions from 123 studies, published in 2019, established that an ADC cut-off value of $1.00 \times 10^{-3} \mathrm{~mm}^{2} / \mathrm{s}$ can be recommended for distinguishing breast cancers from benign lesions. This result was independent on Tesla strength, choice of $b$ values, and measure methods (whole lesion measure vs. estimation of ADC in a single area) [33]. In another prospective multicenter study of 107 women with MRI-detected BI-RADS 3, 4, or 5 lesions, Rahbar et al. [34] evaluated the diagnostic performance of centrally measured ADC values to identify optimal ADC thresholds to reduce unnecessary biopsies. They identified an ADC threshold of $1.53 \times 10^{-3} \mathrm{~mm}^{2} / \mathrm{s}$, which lowered the biopsy rate by $20.9 \%$. The authors recommended that an established threshold should be validated in future studies. In 2021, Clauser et al. [7] conducted a retrospective, multicentric, cross-sectional study in five sites in three European countries to evaluate whether the pre-defined ADC cut-off value by Rahbar et al. [34] allows the downgrading of BI-RADS 4 lesions on contrast-enhanced MRI, thus avoiding unnecessary biopsies. This study included 657 female patients with 696 BI-RADS 4 lesions. Applying the investigated ADC cut-off, sensitivity was $96.6 \%$ and the potential reduction in unnecessary biopsies was found to be $32.6 \%$. 
In our study, with the application of $\mathrm{ADC} \leq 1.11 \times 10^{-3} \mathrm{~mm}^{2} / \mathrm{s}$ as the optimum cut-off value distinguishing malignant from benign tumors, we had two malignant lesions that showed "false-negative results", which are both DCIS with ADC values, respectively, 1.3 and $1.21 \times 10^{-3} \mathrm{~mm}^{2} / \mathrm{s}$, and two lesions which were just at the cut-off values of inflammatory carcinoma and mucinous carcinoma, respectively.

We also had one "false-positive result" —an abscess with an ADC value of $0.89 \times$ $10^{-3} \mathrm{~mm}^{2} / \mathrm{s}$ (Figure 6) and another abscess at the cut-off value of $1.11 \times 10^{-3} \mathrm{~mm}^{2} / \mathrm{s}$. The highest ADC value was for fibroadenoma-2.01 $\times 10^{-3} \mathrm{~mm}^{2} / \mathrm{s}$.

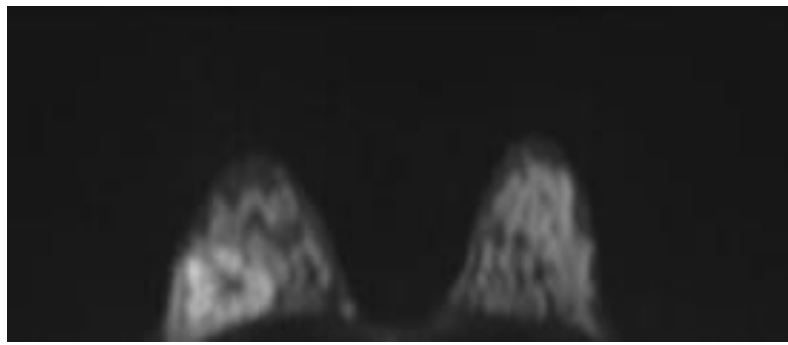

(A)

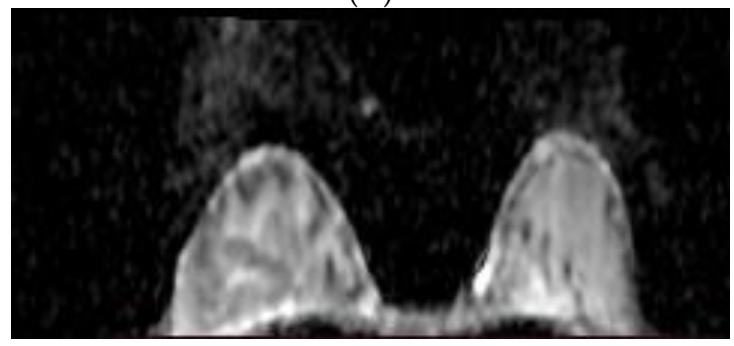

(B)

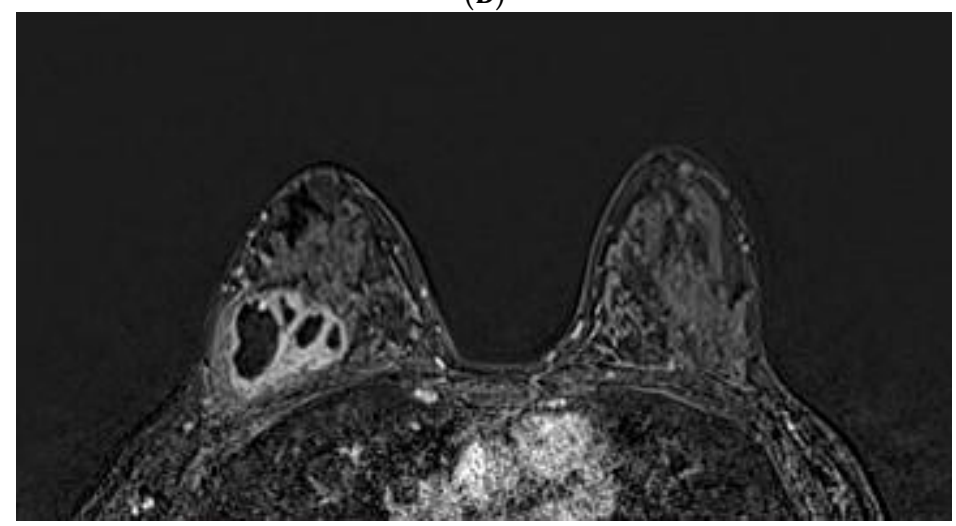

(C)

Figure 6. Breast MRI in a 29-year-old patient with an abscess: (A) DWI (b=800 $\left.\mathrm{mm}^{2} / \mathrm{s}\right)$; (B) ADC value $0.89 \times 10^{-3} \mathrm{~mm}^{2} / \mathrm{s}$; and (C) DCE-MRI (subtraction image).

Additionally, we calculated the ADC ratio by dividing the ADC value of the lesion and the ADC value of the normal glandular tissue. A significantly lower ADC ratio was observed in the patients with malignant tumors (mean $0.66 \pm 0.13$, range 0.43 to 1.06 ) versus the patients with benign lesions (mean $1.12 \pm 0.23$, rang 0.54 to 1.79 ), $p<0.001$. A cut-off point of $\mathrm{ADC}$ ratio $\leq 0.87$ was established as the optimum criterion for differentiating malignant from benign breast tumors, characterized by $94.23 \%$ sensitivity, $91.43 \%$ specificity, and a diagnostic accuracy of $95 \%(\mathrm{AUC}=0.950,95 \% \mathrm{CI}: 0.881$ to $0.985, p<0.001)$. In our study, the calculated ADC ratio did not additionally improve the results received when using ADC values only. Several studies in the literature have reported increased sensitivity and specificity when using the ADC ratio: Azab and Ibrahim [18] reported a cut-off ADC ratio of 0.9 in the differentiation between benign and malignant breast lesions with a 
sensitivity of $92.2 \%$ and a specificity of $94.4 \%$ and Sahin and Aribal [35] reported a cut-off ADC ratio of 0.8 with a sensitivity of $91.4 \%$ and a specificity of $100 \%$.

Although we believe that the data from our study are valuable, we must mention some limitations. First, this study was retrospective and existing artifacts could not be corrected. Second, the data were obtained and analyzed by one radiologist and in one center. Third, the distribution of patients in the different histological subgroups showed that invasive ductal carcinoma was dominant in the malignant group and fibroadenoma in the benign group. Thus, due to the small number of patients, we were unable to perform a subgroup analysis and test the relation between the ADC value and ADC ratio in different benign and malignant subgroups. This could give us more information in relation to the biological nature of the lesions, which are worth being in the scope of future investigations.

Despite the aforementioned limitations, we believe that our study presents valuable data about $\mathrm{ADC}$ values, $\mathrm{ADC}$ ratios, and their potential for differentiating benign from malignant breast lesions-and thus adds to the existing knowledge.

\section{Conclusions}

In conclusion, the data from our study demonstrated the diagnostic potential of DWI, $\mathrm{ADC}$ value, and $\mathrm{ADC}$ ratio in differentiating malignant from benign breast lesions. Based on our data, we would propose the usage of an ADC value of $\leq 1.11 \times 10^{-3} \mathrm{~mm}^{2} / \mathrm{s}$ as the optimum cut-off level to distinguish benign from malignant breast lesions. As the ADC ratio did not further improve the predictive potential and diagnostic accuracy of ADC values, we consider the ADC value as reliable as the ADC ratio. Both measurements could be implemented additionally to well-established imaging techniques to more accurately predict the nature of the breast lesions. This would help avoid unnecessary or even risky interventional diagnostic procedures. We realize that the ADC value around the threshold still presents a challenge and will require special attention when making a particular diagnostic decision. However, this does not lower the importance of the technique as a part of the comprehensive diagnostic evaluation of breast lesions.

Author Contributions: Conceptualization, S.T.; methodology, S.T.; software, D.D.; validation, S.T. and D.D.; formal analysis, S.T. and K.D.; investigation, S.T., A.V. and K.D.; resources, K.S.; data curation, S.T.; writing-original draft preparation, S.T., A.V. and K.D.; writing—review and editing, V.A. and K.S.; visualization, A.V. and D.D.; supervision, V.A.; project administration, S.T. and K.D.; surgical interventions, P.U. All authors have read and agreed to the published version of the manuscript.

Funding: This research received no external funding.

Institutional Review Board Statement: This study was conducted in accordance with the Declaration of Helsinki, and approved by the Institutional Board of the Independent Medical Diagnostic Laboratory “Mediscan” (protocol number 23/01.09.2021, date of approval: 1 September 2021).

Informed Consent Statement: Informed consent was obtained from all subjects involved in the study. Written informed consent was obtained from the patient(s) to publish this paper.

Data Availability Statement: Not applicable.

Conflicts of Interest: The authors declare no conflict of interest.

\section{References}

1. Sasieni, P.D.; Shelton, J.; Ormiston-Smith, N.; Thomson, C.S.; Silcocks, P.B. What is the lifetime risk of developing cancer? The effect of adjusting for multiple primaries. Br. J. Cancer 2011, 105, 460-465. [CrossRef]

2. Sung, H.; Ferlay, J.; Siegel, R.L.; Laversanne, M.; Soerjomataram, I.; Jemal, A.; Bray, F. Global Cancer Statistics 2020: Globocan Estimates of Incidence and Mortality Worldwide for 36 Cancers in 185 Countries. CA Cancer J. Clin. 2021, 71, 209-249. [CrossRef]

3. Paepke, S.; Metz, S.; Brea Salvago, A.; Ohlinger, R. Benign Breast Tumours-Diagnosis and Management. Breast Care 2018, 13, 403-412. [CrossRef]

4. Stachs, A.; Stubert, J.; Reimer, T.; Hartmann, S. Benign Breast Disease in Women. Dtsch. Arztebl. Int. 2019, 116, 565-574. [CrossRef]

5. Mann, R.M.; Balleyguier, C.; Baltzer, P.A.; Bick, U.; Colin, C.; Cornford, E.; Evans, A.N.; Fallenberg, E.M.; Forrai, G.; Fuchsjäger, M.H.; et al. European Society of Breast Imaging (EUSOBI), with language review by Europa Donna-The European Breast Cancer Coalition. Breast MRI: EUSOBI recommendations for women's information. Eur. Radiol. 2015, 25, 3669-3678. [CrossRef] 
6. $\quad$ Mann, R.M.; Cho, N.; Moy, L. Breast MRI: State of the Art. Radiology 2019, 292, 520-536. [CrossRef]

7. Clauser, P.; Krug, B.; Bickel, H.; Dietzel, M.; Pinker, K.; Neuhaus, V.F.; Marino, M.A.; Moschetta, M.; Troiano, N.; Helbich, T.H.; et al. Diffusion-weighted Imaging Allows for Downgrading MR BI-RADS 4 Lesions in Contrast- enhanced MRI of the Breast to Avoid Unnecessary Biopsy. Clin. Cancer Res. 2021, 27, 1941-1948. [CrossRef]

8. Amornsiripanitch, N.; Bickelhaupt, S.; Shin, H.J.; Dang, M.; Rahbar, H.; Pinker, K.; Partridge, S.C. Diffusion-weighted MRI for Unenhanced Breast Cancer Screening. Radiology 2019, 293, 504-520. [CrossRef]

9. Amitai, Y.; Scaranelo, A.; Menes, T.S.; Fleming, R.; Kulkarni, S.; Ghai, S.; Freitas, V. Can breast MRI accurately exclude malignancy in mammographic architectural distortion? Eur. Radiol. 2020, 30, 2751-2760. [CrossRef]

10. Bakker, M.F.; de Lange, S.V.; Pijnappel, R.M.; Mann, R.M.; Peeters, P.H.M.; Monninkhof, E.M.; Emaus, M.J.; Loo, C.E.; Bisschops, R.H.; Lobbes, M.B.; et al. Dense Trial Study Group. Supplemental MRI Screening for Women with Extremely Dense Breast Tissue. N. Engl. J. Med. 2019, 381, 2091-2102. [CrossRef]

11. Amandeep, S.; Jasmin, P.; Kamlesh, G.; Gauaravdeep, S. Breast Lesion Characterisation with Diffusion- Weighted Imaging versus Dynamic Contrast- Enhanced- MRI: A Prospective Observational Study in a Tertiary Care Hospital. EMJ Radiol. $2021,2,7582$. [CrossRef]

12. Le Bihan, D. Diffusion MRI: What water tells us about the brain. EMBO Mol. Med. 2014, 6, 569-573. [CrossRef]

13. Baliyan, V.; Das, C.J.; Sharma, R.; Gupta, A.K. Diffusion weighted imaging: Technique and applications. World J. Radiol. 2016, 8 , 785-798. [CrossRef]

14. Woodhams, R.; Ramadan, S.; Stanwell, P.; Sakamoto, S.; Hata, H.; Ozaki, M.; Kan, S.; Inoue, Y. Diffusion-weighted imaging of the breast: Principles and clinical applications. Radiographics 2011, 31, 1059-1084. [CrossRef]

15. Guo, Y.; Cai, Y.Q.; Cai, Z.L.; Gao, Y.G.; An, N.Y.; Ma, L.; Mahankali, S.; Gao, J.-H. Differentiation of clinically benign and malignant breast lesions using diffusion-weighted imaging. J. Magn. Reson. Imaging 2002, 16, 172-178. [CrossRef]

16. Partridge, S.C.; Nissan, N.; Rahbar, H.; Kitsch, A.E.; Sigmund, E.E. Diffusion-weighted breast MRI: Clinical applications and emerging techniques. J. Magn. Reson. Imaging 2017, 45, 337-355. [CrossRef]

17. Woodhams, R.; Matsunaga, K.; Iwabuchi, K.; Kan, S.; Hata, H.; Kuranami, M.; Watanabe, M.; Hayakawa, K. Diffusion-weighted imaging of malignant breast tumors: The usefulness of apparent diffusion coefficient (ADC) value and ADC map for the detection of malignant breast tumors and evaluation of cancer extension. J. Comput. Assist. Tomogr. 2005, 29, 644-649. [CrossRef]

18. Azab, E.A.; Ibrahim, M.E. Diffusion weighted (DW) MRI role in characterization of breast lesions using absolute and normalized ADC values. Egypt. J. Radiol. Nucl. Med. 2018, 47, 564-570. [CrossRef]

19. Okuma, H.; Sudah, M.; Kettunen, T.; Niukkanen, A.; Sutela, A.; Masarwah, A.; Kosma, V.-M.; Auvinen, P.; Mannermaa, A.; Vanninen, R. Peritumor to tumor apparent diffusion coefficient ratio is associated with biologically more aggressive breast cancer features and correlates with the prognostication tools. PLoS ONE 2020, 15, e0235278. [CrossRef]

20. Surov, A.; Clauser, P.; Chang, Y.W.; Li, L.; Martincich, L.; Partridge, S.C.; Kim, J.Y.; Meyer, H.J.; Wienke, A. Can diffusion-weighted imaging predict tumor grade and expression of Ki-67 in breast cancer? A multicenter analysis. Breast Cancer Res. 2018, 20, 58. [CrossRef]

21. Baxter, G.C.; Graves, M.J.; Gilbert, F.J.; Patterson, A.J. A Meta-analysis of the Diagnostic Performance of Diffusion MRI for Breast Lesion Characterization. Radiology 2019, 291, 632-641. [CrossRef]

22. Kim, J.Y.; Suh, H.B.; Kang, H.J.; Shin, J.K.; Choo, K.S.; Nam, K.J.; Lee, S.W.; Jung, Y.L.; Bae, Y.T. Apparent diffusion coefficient of breast cancer and normal fibroglandular tissue in diffusion-weighted imaging: The effects of menstrual cycle and menopausal status. Breast Cancer Res. Treat 2016, 157, 31-40. [CrossRef]

23. Maric, J.; Boban, J.; Ivkovic-Kapicl, T.; Djilas, D.; Vucaj-Cirilovic, V.; Bogdanovic-Stojanovic, D. Differentiation of Breast Lesions and Distinguishing Their Histological Subtypes Using Diffusion-Weighted Imaging and ADC Values. Front. Oncol. 2020, 10, 332 [CrossRef]

24. Rabasco, P.; Caivano, R.; Simeon, V.; Dinardo, G.; Lotumolo, A.; Gioioso, M.; Villonio, A.; Iannelli, G.; D'Antuono, F.; Zandolino, A.; et al. Can diffusion-weighted imaging and related apparent diffusion coefficient be a prognostic value in women with breast cancer? Cancer Investig. 2017, 35, 92-99. [CrossRef]

25. Akın, Y.; Uğurlu, M.Ü.; Kaya, H.; Arıbal, E. Diagnostic Value of Diffusion-weighted Imaging and Apparent Diffusion Coefficient Values in the Differentiation of Breast Lesions, Histopathologic Subgroups and Correlation with Prognostic Factors using 3.0 Tesla MR. J. Breast Health 2016, 12, 123-132. [CrossRef]

26. Kuhl, C.K.; Mielcareck, P.; Klaschik, S.; Leutner, C.; Wardelmann, E.; Gieseke, J.; Schild, H. Dynamic breast MR imaging: Are signal intensity time course data useful for differential diagnosis of enhancing lesions. Radiology 1999, 211, 101-110. [CrossRef]

27. Baltzer, P.; Mann, R.M.; Iima, M.; Sigmund, E.E.; Clauser, P.; Gilbert, F.J.; Martincich, L.; Partridge, S.C.; Patterson, A.; Pinker K.; et al. EUSOBI international Breast Diffusion-Weighted Imaging working group. Diffusion-weighted imaging of the breast-a consensus and mission statement from the EUSOBI International Breast Diffusion-Weighted Imaging working group. Eur. Radiol. 2020, 30, 1436-1450. [CrossRef]

28. Bozkurt, T.B.; Koc, G.; Sezgin, G.; Altay, C.; Gelal, M.F.; Oyar, O. Value of apparent diffusion coefficient values in differentiating malignant and benign breast lesions. Balk. Med. J. 2016, 33, 294-300. [CrossRef]

29. Marini, C.; Lacconi, C.; Giannelli, M.; Cilotti, A.; Moretti, M.; Bartolozzi, C. Quantitative diffusion-weighted MR imaging in the differential diagnosis of breast lesion. Eur. Radiol. 2007, 17, 2646-2655. [CrossRef] 
30. Partridge, S.C.; Amornsiripanitch, N. DWI in the Assessment of Breast Lesions. Top. Magn. Reson. Imaging 2017, 26, 201-209. [CrossRef]

31. Lee, S.H.; Shin, H.J.; Moon, W.K. Diffusion-Weighted Magnetic Resonance Imaging of the Breast: Standardization of Image Acquisition and Interpretation. Korean J. Radiol. 2021, 22, 9-22. [CrossRef]

32. Kul, S.; Cansu, A.; Alhan, E. Contribution of diffusion weighted imaging to dynamic contrast enhanced MRI in characterization of breast tumors. AJR 2011, 196, 210-217. [CrossRef]

33. Rahbar, H.; Zhang, Z.; Chenevert, T.L.; Romanoff, J.; Kitsch, A.E.; Hanna, L.G.; Harvey, S.M.; Moy, L.; DeMartini, W.B.; Dogan, B.; et al. Utility of Diffusion-weighted Imaging to Decrease Unnecessary Biopsies Prompted by Breast MRI: A Trial of the ECOG-ACRIN Cancer Research Group (A6702). Clin. Cancer Res. 2019, 25, 1756-1765. [CrossRef]

34. Surov, A.; Meyer, H.J.; Wienke, A. Can apparent diffusion coefficient (ADC) distinguish breast cancer from benign breast findings? A meta-analysis based on 13847 lesions. BMC Cancer 2019, 19, 955. [CrossRef]

35. Sahin, C.; Aribal, E. The role of apparent diffusion coefficient values in the differential diagnosis of breast lesions in diffusionweighted MRI. Diagn. Interv. Radiol. 2013, 19, 457-462. [CrossRef] 